\title{
Psychiatric Morbidity among Spouses of Men with Alcohol Dependence
}

\author{
${ }^{1}$ Vishal A Shah, ${ }^{2}$ Prakash Behere, ${ }^{3}$ KK Mishra, ${ }^{4}$ Animesh Sharma, ${ }^{5}$ Kanika Kumar
}

\begin{abstract}
Objective: To assess the common mental disorders among spouses of men with alcohol dependence and to compare common mental disorders among spouses of alcoholics and nonalcoholics.
\end{abstract}

Study design: This was a cross-sectional controlled study. We evaluated 50 cases (including the indoor and outdoor patients) whose husbands were diagnosed as having alcohol dependence and 50 controls whose husbands had no alcohol dependence but some other illness, admitted to our rural medical college using the global mental health assessment tool-primary care (GMHAT-PC) version including the sociodemographic profile sheet and history of patient's illness.

Results: Anxiety (16\%) and depression (36\%) were higher in wives of alcohol-dependent men. Stress was higher (6\%) in cases as compared with controls (4\%). When comparing diagnosis and age-wise distribution, depression was higher in cases (28\%) as compared with controls (14\%) in age group of 31 to 40 . There were $23(46 \%)$ out of 50 spouses of men with alcohol dependence syndrome, whose diagnosis by GMHAT-PC came out as no mental illness; still they had some score in the anxiety rating, but this score was not enough for them to be diagnosed under anxiety disorder. Even in controls, anxiety score to a certain extent was present in $26 \%$ spouses. The GMHAT-PC self-harm scoring system was used to assess the risk of self-harm. It was found that three $(6 \%)$ spouses had mild suicidal risk and one ( $2 \%$ ) had severe suicidal risk, whereas in controls, it was absent.

Conclusion: Alcohol abuse is associated with an increased risk of committing criminal offences. An alcoholic can disrupt the routine family life. The women are primary caregivers in most of these cases. Therefore, understanding mental health status of spouses of alcoholics is of utmost importance. It can help in early detection of psychiatric morbidities and help in early intervention.

Keywords: Alcohol dependence, Global mental health assessment tool-primary care, Psychiatric morbidity, Spouses of men with alcohol dependence.

\footnotetext{
${ }^{1,4,5}$ Resident, ${ }^{2,3}$ Professor and Head

1,3-5 Department of Psychiatry, Jawaharlal Nehru Medical College, Wardha, Maharashtra, India

${ }^{2}$ Department of Psychiatry, D.Y. Patil University, Kolhapur Maharashtra, India

Corresponding Author: Vishal A Shah, Resident, Department of Psychiatry, Jawaharlal Nehru Medical College, Wardha Maharashtra, India, Phone: +919561662226, e-mail: vishal2k07@gmail.com
}

How to cite this article: Shah VA, Behere P, Mishra KK, Sharma A, Kumar K. Psychiatric Morbidity among Spouses of Men with Alcohol Dependence. Int J Recent Surg Med Sci 2017;3(1):10-14.

\section{Source of support: Nil}

\section{Conflict of interest: None}

\section{INTRODUCTION}

Alcohol is a natural substance made by fermenting sugar with yeast spores. Although there are many kinds of alcohols, the kind found in alcoholic beverages is known scientifically as ethyl alcohol and chemically as $\mathrm{C}_{2} \mathrm{H}_{5} \mathrm{OH}$. Different alcoholic beverages are formed by using various sources of sugar for the fermentation process. Distilled alcohols (e.g., whiskey, scotch, gin, vodka, and other "hard" liquors) derive their names from further concentration of the alcohol by distillation. The alcohol content varies on the type of beverage.

The ordinary drinker's amount of consumption and type of beverage will vary from day to day and from week to week. Their drinking pattern is influenced by varying internal cues and external circumstances. As dependence advances, the cues are increasingly related to relief or avoidance of alcohol withdrawal, and the personal drinking repertoire becomes increasingly narrowed.

As per 2010 statistics, $7.5 \%$ of the world population indulges in heavy episodic drinking, and the worldwide alcohol per capita consumption is equal to $6.2 \mathrm{~L}$ of pure alcohol being consumed per person over the age of 15 years. ${ }^{1}$ According to 2012 statistics, it is believed that 3.3 million (5.9\%) of all global deaths and 139 million of disability-adjusted life years (5.1\%) of the global burden of disease and injury were attributable to alcohol consumption alone. ${ }^{1}$ These values have led the harmful use of alcohol to be ranked as the fifth most common risk factor for disease, disability, and death throughout the world in 2010, ascending from the eigth rank in 1990. ${ }^{2}$

A significant number of the spouses, who have partners suffering from alcoholism, are now themselves being diagnosed with various disorders as a direct result of their partners' drinking. A study conducted in India showed that $65 \%$ of the spouses with partners diagnosed with alcoholism had psychiatric disorders ranging from mood and anxiety disorders to major depressive disor$\operatorname{ders}(43 \%)^{3}$ 
Intimate partner violence abbreviated as IPV has risen to the level of a major health problem. There is a strong causal relationship between IPV and alcoholism, as alcohol impairs a person's judgment and cognitive function, which in addition to reducing self-control leaves the person incapable of reaching a nonviolent solution to resolve marital conflicts.

In India, cultural barriers prevent women from speaking out about marital discord, and there is a sense of acceptance of the spouse's behavior despite continued abuse. These women become the primary caregivers of their spouses and suffer in silence from a myriad of physical and psychosocial problems.

The spouses of alcoholics face difficulty in reaching the mental health facility in the community, which is further worsened by the extreme deficit of mental health workers in India.

Mental health disorders account for nearly a sixth of all health-related disorders. Yet, we just have 0.02 psychologists and 0.4 psychiatrists per 100,000 population, and 0.25 mental health beds per 10,000 population.

Early and accurate detection of mental health problems in spouses of men with alcohol dependence followed by an appropriate management plan focusing on recovery and return to work would help to reduce the global burden on health and society caused by mental diseases. ${ }^{4}$ We can use global mental health assessment tool-primary care version (GMHAT-PC) (software) for screening the community, which gives the diagnosis and also the differential diagnosis according to International Classification of Diseases (ICD)-10 criteria.

\section{MATERIALS AND METHODS}

Based on this background, we evaluated 50 cases whose husbands were diagnosed as having alcohol dependence and 50 controls whose husbands had no alcohol dependence but some other illness, admitted to our rural medical college from January 1, 2015 to June 30, 2016. After getting ethical clearance, the data were collected electronically on the GMHAT-PC, which also included the sociodemographic profile sheet for the patient and history of patient's illness.

The GMHAT-PC is a computerized clinical assessment tool developed to assess and identify mental health problems in primary and general health care. The assessment program starts with basic instructions giving details on how to use the tool and rate the symptoms accordingly. The main diagnosis is derived using a tiered model and constructed around ICD-10. The program takes into consideration the severity of symptoms (moderate to severe). It also generates alternative diagnoses and comorbid conditions based on the presence of symptoms of other disorders. It also includes an assessment of self-harm risk. Also, the program includes management guidelines for these disorders.

Statistical analysis was done by using descriptive and inferential statistics using chi-square test, and software used in the analysis were Statistical Package for the Social Sciences 17.0 version and Graph Pad Prism 6.0 version; the $t$-test was used to compare the differences and $p<0.05$ was considered as level of significance.

\section{RESULTS}

A total of 100 subjects (50 each in cases and controls) were interviewed and the following observations were made. All the diagnosis was made by GMHAT-PC tool, which is ICD-10 based. The maximum subjects were in the age group of 21 to 40 years in cases, while in controls, subjects were in age group of 41 to 60 years. The mean age in cases was $40.68 \pm 7.96$, while in controls, it was $42.44 \pm 10.35$ years. In spouses of men with alcohol dependence, anxiety $(16 \%)$ and depression $(36 \%)$ were found to be higher, as compared with controls (12 and $14 \%$ respectively). Stress (6\%) was higher in cases as compared with controls (4\%). The above difference was statistically significant (Table 1, Graph 1).

Table 1: Psychiatric morbidity among spouses of men with alcohol dependence syndrome and controls

\begin{tabular}{llll}
\hline $\begin{array}{l}\text { Psychiatric } \\
\text { morbidity }\end{array}$ & $\begin{array}{l}\text { Case } \\
\text { group }\end{array}$ & $\begin{array}{l}\text { Control } \\
\text { group }\end{array}$ & $\chi^{2}$-value \\
\hline Anxiety & $8(16 \%)$ & $6(12 \%)$ & $12.07 \mathrm{p}=0.033, \mathrm{~S}$ \\
Depression & $18(36 \%)$ & $7(14 \%)$ & \\
Phobia + stress & $1(2 \%)$ & $0(0 \%)$ & \\
Stress & $3(6 \%)$ & $2(4 \%)$ \\
Psychotic disorder & $1(2 \%)$ & $0(0 \%)$ \\
No mental illness & $19(38 \%)$ & $35(70 \%)$ \\
Total & $50(100 \%)$ & $50(100 \%)$ \\
\hline
\end{tabular}

S: Significant

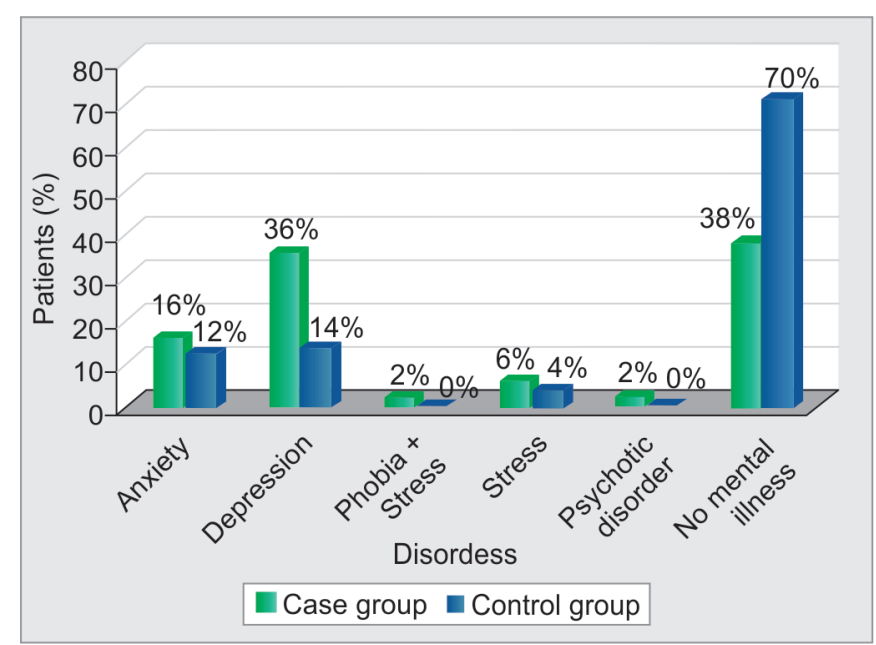

Graph 1: Psychiatric morbidity among spouses of men with alcohol dependence syndrome and controls 
In cases, depression (36\%) was the highest predominantly in the age group of 31 to 40 years, which was followed by anxiety $(16 \%)$ predominantly in the age group of 41 to 50 years. Stress (6\%) was more common in the 21 to 30 years age group. Phobia + stress $(2 \%)$ was found in the age group 41 to 50 years. One case (2\%) of psychotic disorder was found in the age group of 51 to 60 years. The above difference was statistically significant (Table 1, Graph 1).

In controls, depression (14\%) was the highest and predominantly in the age group of 31 to 40 years, followed by anxiety (12\%), which was predominant in the age group of 21 to 30 years. Stress (4\%) was equal in both 21 to 30 years and 51 to 60 years age group. The above difference was statistically significant (Table 2, Graph 2).

When comparing diagnosis and age-wise distribution, depression was higher in cases (28\%) as compared with controls (14\%) in the age group of 31 to 40 years, and overall difference was statistically significant (Table 2, Graph 2).

A total of $23(46 \%)$ out of 50 spouses of men with alcohol dependence syndrome, whose diagnosis by GMHAT-PC came out as no mental illness, still had some score in the anxiety rating, but this score was not enough for them to be diagnosed as anxiety disorder. Even in controls, anxiety score to some extent was present in 13 (26\%) spouses out of 50 . This difference was statistically significant.

A total of 18 (36\%) out of 50 spouses of men with alcohol dependence syndrome, whose diagnosis by GMHAT-PC came out as no mental illness, had some score in the depression rating, but this score was not enough for them to be diagnosed as depressive disorder. Even in controls, depression score to some extent was present in 7 (14\%) spouses out of 50 . This difference was statistically significant.

A total of $8(16 \%)$ out of 50 spouses of men with alcohol dependence syndrome, whose diagnosis by GMHAT-PC came out as no mental illness, still had some score in the stress rating, but this score was not enough for them to be diagnosed as stress disorder. Even in controls, stress score to some extent was present in 6 $(12 \%)$ spouses out of 50 . This difference was statistically nonsignificant.

The risk of self-harm in cases and controls was observed. It was found by the GMHAT-PC self-harm scoring system that three (6\%) spouses had mild suicidal risk and one ( $2 \%$ ) had severe suicidal risk according to

Table 2: Diagnosis and age-wise distribution in cases and controls

\begin{tabular}{|c|c|c|c|c|c|c|c|c|}
\hline \multirow[b]{2}{*}{ Psychiatric morbidity } & \multicolumn{2}{|c|}{ 21-30 years } & \multicolumn{2}{|c|}{$31-40$ years } & \multicolumn{2}{|c|}{$41-50$ years } & \multicolumn{2}{|c|}{$51-60$ years } \\
\hline & $\begin{array}{l}\text { Study } \\
\text { group }\end{array}$ & $\begin{array}{l}\text { Control } \\
\text { group }\end{array}$ & $\begin{array}{l}\text { Study } \\
\text { group }\end{array}$ & $\begin{array}{l}\text { Control } \\
\text { group }\end{array}$ & $\begin{array}{l}\text { Study } \\
\text { group }\end{array}$ & $\begin{array}{l}\text { Control } \\
\text { group }\end{array}$ & $\begin{array}{l}\text { Study } \\
\text { group }\end{array}$ & $\begin{array}{l}\text { Control } \\
\text { group }\end{array}$ \\
\hline Anxiety & $3(6 \%)$ & $3(6 \%)$ & $1(2 \%)$ & $0(0 \%)$ & $3(6 \%)$ & $2(4 \%)$ & $1(2 \%)$ & $1(2 \%)$ \\
\hline Depression & $0(0 \%)$ & $0(0 \%)$ & $14(28 \%)$ & $7(14 \%)$ & $2(4 \%)$ & $0(0 \%)$ & $2(4 \%)$ & $0(0 \%)$ \\
\hline Phobia + stress & $0(0 \%)$ & $0(0 \%)$ & $0(0 \%)$ & $0(0 \%)$ & $1(2 \%)$ & $0(0 \%)$ & $0(0 \%)$ & $0(0 \%)$ \\
\hline Stress & $2(4 \%)$ & $1(2 \%)$ & $1(2 \%)$ & $0(0 \%)$ & $0(0 \%)$ & $0(0 \%)$ & $0(0 \%)$ & $1(2 \%)$ \\
\hline Psychotic disorder & $0(0 \%)$ & $0(0 \%)$ & $0(0 \%)$ & $0(0 \%)$ & $0(0 \%)$ & $0(0 \%)$ & $1(2 \%)$ & $0(0 \%)$ \\
\hline No mental illness & $0(0 \%)$ & $6(12 \%)$ & $7(14 \%)$ & $3(6 \%)$ & $10(20 \%)$ & $15(30 \%)$ & $2(4 \%)$ & $11(22 \%)$ \\
\hline Total & $5(10 \%)$ & $10(20 \%)$ & $23(46 \%)$ & $10(20 \%)$ & $16(32 \%)$ & $17(34 \%)$ & $6(12 \%)$ & $13(26 \%)$ \\
\hline$\chi^{2}$-value & \multicolumn{2}{|c|}{$0.45, p=0.50, N S$} & \multicolumn{2}{|c|}{$1.91, p=0.38, N S$} & \multicolumn{2}{|c|}{$3.20, p=0.20, N S$} & \multicolumn{2}{|c|}{$7.50, p=0.05, N S$} \\
\hline$\chi^{2}$-value & \multicolumn{8}{|c|}{$189.10, p=0.0001, S$} \\
\hline
\end{tabular}

S: Significant; NS: Not significant

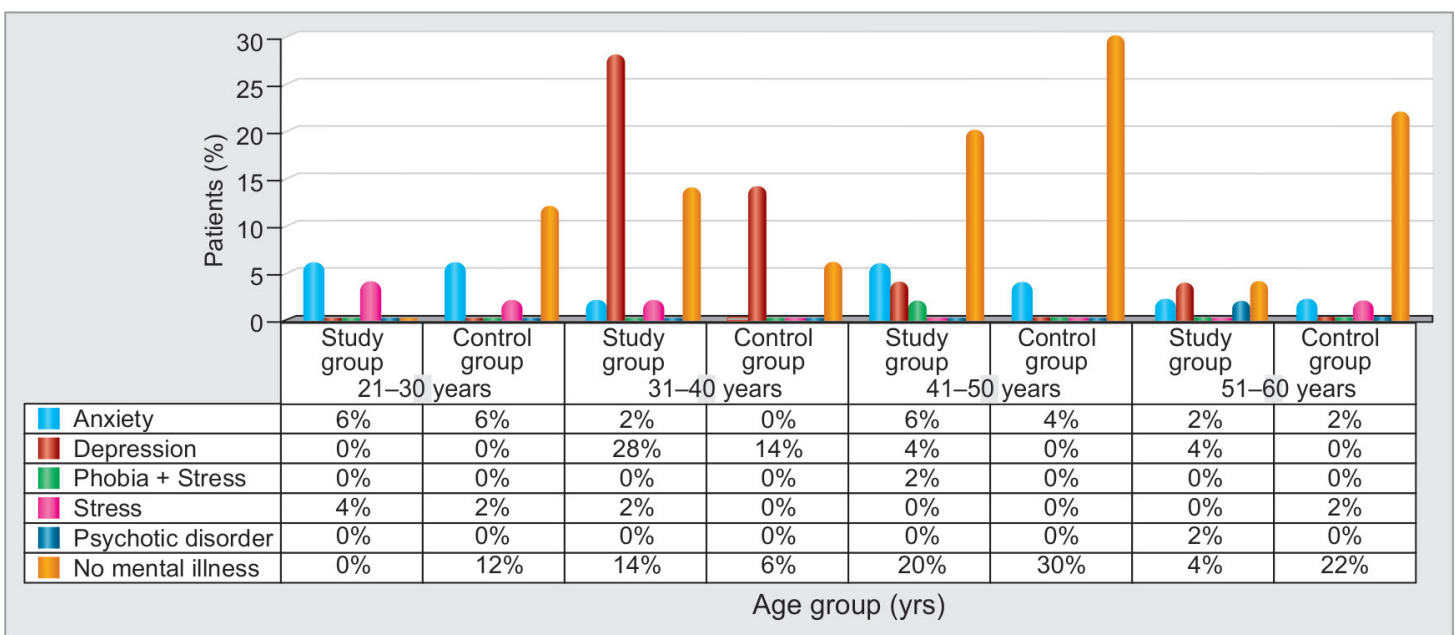

Graph 2: Diagnosis and age-wise distribution in cases and controls 


\begin{tabular}{|c|c|c|c|}
\hline Suicidal risk & $\begin{array}{l}\text { Case group } \\
(n=50)\end{array}$ & $\begin{array}{l}\text { Control group } \\
(n=50)\end{array}$ & $\chi^{2}$-value \\
\hline Mild & $3(6 \%)$ & $0(0 \%)$ & $8.33, p=0.015, S$ \\
\hline Sever & $1(2 \%)$ & $0(0 \%)$ & \\
\hline No risk & $46(92 \%)$ & $50(100 \%)$ & \\
\hline Total & $50(100 \%)$ & $50(100 \%)$ & \\
\hline
\end{tabular}

S: Significant

score, whereas in controls, it was absent. The difference was statistically significant (Table 3, Graph 3).

\section{DISCUSSION}

In this study, it was observed that the maximum subjects were between the age of 21 and 40 years (56\%) in cases, while in controls they were between 41 and 60 years of age (60\%). In similar studies, it was found that the majority of spouses of men with alcohol dependence syndrome were in the age group of 24 to 50 years, which was in concordance with our study. $3,5,6$

In this study, it was also seen that the psychiatric morbidities among spouses of men with alcohol dependence were significantly higher in the cases as compared with controls. It was observed in studies conducted by Mammen et $\mathrm{al}^{7}$ and Bagul et $\mathrm{al}^{6}$ that prevalence of psychiatric morbidities in wives of men with alcohol dependence syndrome was similar.

It was observed in this study that diagnosis of anxiety was higher in spouses of alcoholic husbands $(16 \%)$ as compared with those of nonalcoholic husbands $(12 \%)$. These findings were in concordance with findings of ${\text { Bagul et } \mathrm{al}^{6} \text { and Gohil et al. }}^{8}$

A prominent finding noticed in this study was that 18 (36\%) spouses of alcohol-dependent men had depression, whereas in controls, it was seen in only 7 (14\%) spouses. These findings were similar to the studies conducted in similar areas in different parts of the world. This can be attributed to the domestic violence faced by the spouses, the economic conditions of the families, and the added stressor of cost of alcohol, thus creating an economic crisis.

Ariyasinghe et $\mathrm{al}^{5}$ conducted a study on the prevalence of major depressive disorder among spouses of men with alcohol dependence, and found the point prevalence of major depressive disorder to be $33.33 \%$, which was higher than their controls. This finding was in concordance with our study.

In a similar study conducted by Kishor et al, ${ }^{3}$ psychiatric morbidities and marital satisfaction among spouses were studied, and they found that the majority of spouses of men with alcohol dependence syndrome were commonly diagnosed with major depressive disorder (43.3\%) followed by dysthymia (35\%), double depression (15\%),

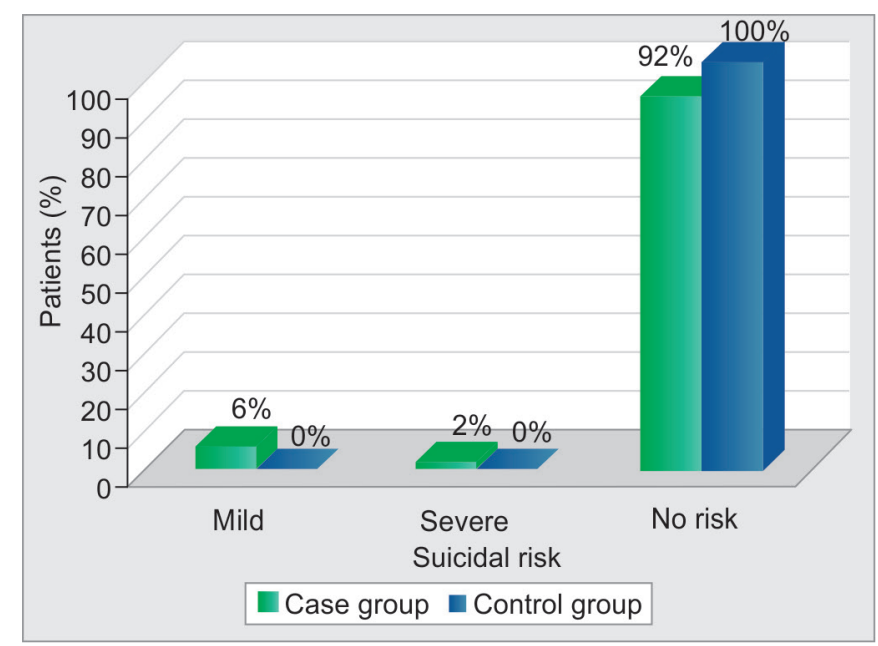

Graph 3: Suicidal risk among spouses of men with alcohol dependence syndrome and controls

and panic disorder (15\%). Bagul et $\mathrm{al}^{6}{ }^{6}$ in their study, found out that $35 \%$ of the spouses had depressive disorders, out of which the majority were diagnosed as major depressive disorder (13.33\%) and dysthymia (21.67\%). Tempier et $\mathrm{al}^{9}$ did a study on psychological distress among spouses of alcoholic men and observed that they have higher levels of psychological distress.

India, being a developing country, faces cultural barriers that prevent women from speaking out about their marital discord and the harsh violence they face at the domestic front. They are made to believe that the general attitude is of acceptance of any kind of abuse.

In the present study, it was noticed that in cases, $6 \%$ had mild and $2 \%$ had severe degree of suicide ideation as compared with controls, where no female had suicide ideation. This result was found to be statistically significant in the study. This can be attributed to the fact that the wives of alcoholics could have more worries and poor functioning due to drinking habits of their husbands. ${ }^{10-12}$

The other important findings noticed were that stress $(6 \%)$ and phobia with stress $(2 \%)$ in cases were significantly higher than controls, which was $4 \%$ and nil respectively.

In this study, it was found that the majority of spouses diagnosed as depression were in the age group of 31 to 40 years, which was similar in both the groups, and it was statistically significant. Bagul et al ${ }^{6}$ found that psychiatric morbidity was more prevalent in spouses of men with alcohol dependence aged between 31 and 50 years. In a study done by Mammen et $\mathrm{al}^{7}{ }^{7}$ they found that $70 \%$ of the spouses having psychiatric morbidity belonged to the age group of 35 to 45 years.

It was noticed that even if GMHAT-PC tool did not diagnose any mental illness, subjects still had scores to some extent in different scoring system. These scores were not severe enough to diagnose them with any mental illness. 
Another finding, which was unusual to the present study, was that one spouse was diagnosed as having psychotic disorder by GMHAT-PC, and after complete assessment by clinician, was diagnosed as paranoid schizophrenia.

Finally, this study summarizes that depressive and anxiety symptoms were higher in spouses of men with alcohol dependence syndrome (cases) as compared with spouses of nonalcohol-dependent men (controls).

\section{CONCLUSION}

Alcohol abuse is associated with an increased risk of committing criminal offences against one's family members including domestic violence, marital conflicts and divorce, marital rape, and assault. An alcoholic can disrupt the routine family life and cause harmful effects that can last a life time. Many studies and anecdotal reports suggest that women, who are married to men who are dependent on alcohol, have poor overall physical and mental health. The women are the primary caregivers in most of these cases. Therefore, understanding the mental health issues of spouses of alcoholics is of utmost importance. It can help in early detection of any psychiatric morbidity, if it exists, and help in early intervention. We have used the GMHAT-PC (computerbased software) as an assessment tool, which gives the diagnosis and also, the differential diagnosis according to ICD-10 criteria. There is higher level of psychological morbidity in spouses of men with alcohol dependence, and it warrants the need for interventions like social and psychiatric support to improve the quality of life of the affected individuals.

\section{IMPLICATIONS OF THIS STUDY}

Psychiatric morbidities faced by spouses of alcoholics are often given insufficient attention and are overlooked completely. The findings from this study are an attempt to bring to focus the distress faced by the spouses and the pressing need to provide proper intervention in this regard. Thus, high rates of psychological distress and morbidity among women whose partners have alcohol dependence need to be addressed either as part of alcohol treatment programs or independently. These issues need to be addressed not only to improve outcomes for the dependent individuals, but also as potentially reversible risk factors that could significantly impact health outcomes of women.

\section{REFERENCES}

1. WHO. Global status report on alcohol and health. Geneva: WHO; 2014.

2. Mersy DJ. Recognition of alcohol and substance abuse. Am Fam Physician 2003 Apr;67(7):1529-1532.

3. Kishor M, Pandit LV, Raguram R. Psychiatric morbidity and marital satisfaction among spouses of men with alcohol dependence. Indian J Psychiatry 2013 Oct-Dec;55(4):360-365.

4. Sharma VK. Detecting mental disorders in primary care. Ment Health Fam Med 2009 Mar;6(1):11-13.

5. Ariyasinghe D, Abeysinghe R, Siriwardhana P, Dassanayake T. Prevalence of major depressive disorder among spouses of men who use alcohol in a rural community in Central Sri Lanka. Alcohol Alcohol 2015 Jan;50(3):328-332.

6. Bagul KR, Deshmukh SB, Bagul MK, Deshmukh PS. Psychiatric morbidity and marital quality among wives of patients with alcohol dependence syndrome. JEBMH 2015 Jun;2(22):3284-3295.

7. Mammen PM, Thilakan P, Solomon S. Pattern of psychiatric morbidity in spouses of patients with alcohol dependence syndrome. JEMDS 2015 Sep;4(71):12309-12315.

8. Gohil JG, Patel MK, Samani MJ. Quality of life and psychiatric morbidity in caregiver of alcohol dependence patients. IOSR J Dent Med Sci 2016 Aug;15(8):98-101.

9. Tempier R, Boyer R, Lambert J, Mosier K, Duncan CR. Psychological distress among female spouses of male at-risk drinkers. Alcohol 2006 Aug;40(1):41-49.

10. Aggarwal A, Sinha SK, Kataria D, Kumar H. Prevalence and predictors of intimate partner violence in alcohol use disorder. J Mental Health Hum Behav 2016 May;21(1):25-31.

11. Foran HM, O'Leary KD. Alcohol and intimate partner violence: a meta-analytic review. Clin Psychol Rev 2008 Oct;28(7):1222-1234.

12. Gilchrist G, Hegarty K, Chondros P, Herrman H, Gunn J. The association between intimate partner violence, alcohol and depression in family practice. BMC Fam Pract 2010 Sep;11:72. 